Abstracta Iranica

Revue bibliographique pour le domaine irano-aryen

Volume 37-38-39 | 2018

Comptes rendus des publications de 2014-2016

\title{
Tobin Hartnell. « Agriculture in Sasanian Persis: Ideology and Practice »
}

\section{Rika Gyselen}

\section{(2) OpenEdition \\ 12 Journals}

\section{Édition électronique}

URL : http://journals.openedition.org/abstractairanica/42624

DOI : 10.4000/abstractairanica.42624

ISBN : 1961-960X

ISSN : 1961-960X

Éditeur :

CNRS (UMR 7528 Mondes iraniens et indiens), Éditions de l'IFRI

Référence électronique

Rika Gyselen, « Tobin Hartnell. "Agriculture in Sasanian Persis: Ideology and Practice » », Abstracta Iranica [En ligne], Volume 37-38-39 | 2018, document 5, mis en ligne le 10 mars 2018, consulté le 28 septembre 2020. URL : http://journals.openedition.org/abstractairanica/42624 ; DOI : https://doi.org/ 10.4000/abstractairanica.42624

Ce document a été généré automatiquement le 28 septembre 2020

Tous droits réservés 


\title{
Tobin Hartnell. « Agriculture in Sasanian Persis: Ideology and Practice »
}

\author{
Rika Gyselen
}

\section{RÉFÉRENCE}

Tobin Hartnell, « Agriculture in Sasanian Persis: Ideology and Practice », in Richard PAYNE, Mehrnoush Soroush (ed.), The Archaeology of Sasanian Politics. Journal of Ancient History, special issue, 2.2), Berlin, De Gruyter, 2014, p. 182-208.

1 L'article est basé sur des données nouvelles fournies par des prospections dans le bassin de la rivière Kur, près de Persépolis qui sont décrites avec précision.

2 Cet exposé explore la relation qui existe entre les implantations de population et l'infrastructure afin d'examiner l'organisation régionale de l'économie du Fars sassanide et sa capacité à faciliter la centralisation du pouvoir.

3 Il est évident que cette région connaît à l'époque sassanide un peuplement dense ( $\mathrm{p}$. 193, Table 2) ce qui ne peut s'expliquer que par une agriculture suffisamment productive laquelle doit pouvoir compter sur une irrigation efficace qui provient essentiellement de barrages sur les cours d'eau. Des vestiges archéologiques mettent en évidence que l'agriculture dans cette région, comme d'ailleurs dans beaucoup d'autres, atteint un caractère « industriel » capable de produire un surplus.

4 Des remarques sur l'administration régionale que met en place le pouvoir sassanide pour contrôler les canaux et lever les taxes laissent quelque peu perplexes. Ainsi par rapport à quoi doit-on comprendre une phrase comme « The title <šahrab> seemingly waxed and waned in importance during the Sasanian Empire... »? (p. 202). 


\section{AUTEURS}

\section{RIKA GYSELEN}

CNRS, Mondes iranien et indien 